\title{
A canine leishmaniasis pilot survey in an emerging focus of visceral leishmaniasis: Posadas (Misiones, Argentina)
}

\author{
Israel Cruz ${ }^{1 *}$, Lucrecia Acosta², Mariana N Gutiérrez ${ }^{3,4}$, Javier Nieto ${ }^{1}$, Carmen Cañavate ${ }^{1}$, Jorge Deschutter ${ }^{3,4}$, \\ Fernando J Bornay-Llinares ${ }^{2}$
}

\begin{abstract}
Background: An increasing number of reports are calling our attention to the worldwide spread of leishmaniasis. The urbanization of zoonotic visceral leishmaniasis (VL) has been observed in different South American countries, due to changes in demographic and ecological factors. In May 2006, VL was detected for the first time in the city of Posadas (Misiones, Argentina). This event encouraged us to conduct a clinical and parasitological pilot survey on domestic dogs from Posadas to identify their potential role as reservoirs for the disease.

Methods: One hundred and ten dogs from the city of Posadas were included in the study. They were selected based on convenience and availability. All dogs underwent clinical examination. Symptomatology related to canine leishmaniasis was recorded, and peripheral blood and lymph node aspirates were collected. Anti-Leishmania antibodies were detected using rK39-immunocromatographic tests and IFAT. Parasite detection was based on peripheral blood and lymph node aspirate PCR targeting the SSUrRNA gene. Molecular typing was addressed by DNA sequence analysis of the PCR products obtained by SSUrRNA and ITS-1 PCR.

Results: According to clinical examination, 69.1\% (76/110) of the dogs presented symptoms compatible with canine leishmaniasis. Serological analyses were positive for $43.6 \%$ (48/110) of the dogs and parasite DNA was detected in 47.3\% (52/110). A total of 63 dogs (57.3\%) were positive by serology and/or PCR. Molecular typing identified Leishmania infantum (syn. Leishmania chagasi) as the causative agent.
\end{abstract}

Conclusions: This work confirms recent findings which revealed the presence of Lutzomyia longipalpis, the vector of $L$. infantum in this area of South America. This new VL focus could be well established, and further work is needed to ascertain its magnitude and to prevent further human $V L$ cases.

\section{Background}

In South America Leishmania infantum (syn. Leishmania chagasi) is the causative agent of visceral leishmaniasis (VL), a systemic infection which is fatal if not treated. The primary vectors are Lutzomyia longipalpis female sand flies, and infected domestic dogs are the main reservoirs [1]. However, Dantas-Torres recently highlighted the need to use proper diagnostic tools to identify the species of Leishmania involved in each case of canine leishmaniasis irrespective of the clinical

\footnotetext{
* Correspondence: cruzi@isciii.es

'WHO Collaborating Centre for Leishmaniasis, Servicio de Parasitología, Centro Nacional de Microbiología, Instituto de Salud Carlos III, Ctra.

Majadahonda-Pozuelo, km 2, 28220 Majadahonda-Madrid, Spain

Full list of author information is available at the end of the article
}

form [2]; this is an important issue to take into account when a new focus is being described.

The worldwide incidence of VL is estimated to be 500000 cases/year, with more than 50000 related deaths. In several areas of the world, there is a clear and disturbing increase in the number of VL cases. For example, in Northeastern Brazil the incidence raised from 1840 cases in year 1998 to 6000 in 2002 [3].

At present, a growing number of reports are calling our attention to a worldwide spread of leishmaniasis, including the urbanization of VL in different South American countries due to changes in demographic and ecological factors [4-8].

\section{Biomed Central}

(c) 2010 Cruz et al; licensee BioMed Central Ltd. This is an Open Access article distributed under the terms of the Creative Commons Attribution License (http://creativecommons.org/licenses/by/2.0), which permits unrestricted use, distribution, and reproduction in any medium, provided the original work is properly cited. 
An example of the latter is the recent report by Salomón, et al. [9] on the first urban VL focus in Posadas (Misiones, Argentina), which appeared in 2006 involving humans and dogs. That work indicated both: i) the presence of Lu. longipalpis in Misiones, where it was reported previously to be anecdotal [10] and ii) the presence of Leishmania sp. infection in 13 out of 27 dogs studied [9]. At present, 58 human VL cases have been reported in Posadas ( 2 in year 2006, 14 in 2007, 17 in 2008, 24 in 2009 and one up to April $30^{\text {th }} 2010$ ), with 6 related deaths [[11], Misiones Ministry of Health personal communication].

Encouraged by the emergence of the first human VL cases, we conducted a canine serological and parasitological pilot survey to: i) identify Leishmania infection in dogs, and thus their possible role as reservoirs, and ii) identify de Leishmania species circulating in this emerging VL focus.

\section{Methods}

\section{Study location}

The serological and parasitological pilot survey was conducted from 1 July to 15 August 2006 in the city of Posadas $\left(27^{\circ} 23^{\prime} \mathrm{S}, 55^{\circ} 54^{\prime} \mathrm{W}\right)$, located in the southwest of Misiones province, Northeast Argentina.

Misiones is bordered by Brazil to the north and by Paraguay to the east. The city of Posadas has a global surface of $324 \mathrm{Km}^{2}$, and is characterized by a subtropical humid climate; annual rain is $1700 \mathrm{~mm}$ and average temperature $21.5^{\circ} \mathrm{C}$. Posadas, which accounts for $29 \%$ of the total population of the province, had an estimated population of 297499 inhabitants in 2008; $98.8 \%$ from urban areas and $32.6 \%$ below the poverty line [12].

\section{Study animals and samples}

Our study was based on a convenience sample of 110 dogs originating from two sources: i) 83 dogs from two different canine shelters, located in the outskirts of Posadas, which admit dogs from the city: 59 from the non-profit civil association 'El Refugio' (Itaembé Miní area) and 24 from the Municipal Animal Health Institute-IMUSA (El Zaimán area), and ii) 27 dogs with owners that attended a local veterinary clinic for routinely care.

All dogs underwent clinical examination by a local veterinarian, searching for symptoms related to canine leishmaniasis (CanL). The presence of one or more of the following was considered for the clinical diagnosis of CanL: lymphadenopathy, onychogryphosis, skin lesions, weight loss, conjunctivitis and alopecia.

After examination one $\mathrm{ml}$ peripheral blood (PB) was obtained from 110 dogs and collected in EDTA-containing tubes; lymph node aspirates (LN) were obtained from 94 dogs and further diluted in $500 \mu \mathrm{l}$ ethanol $70 \%$. Once obtained, samples were stored at $4^{\circ} \mathrm{C}$ until shipment to the WHO Collaborating Centre for Leishmaniasis (Madrid, Spain) for serological and molecular diagnosis.

Informed consent was obtained from each dog owner and from the canine shelter responsible before clinical examination and sampling of the dogs. Research procedures were approved by the corresponding research review boards of Universidad Miguel Hernández and Misiones Ministry of Public Health.

\section{Serological diagnosis}

Anti-Leishmania antibodies detection was performed by two different approaches: a) rK39-immunochromatographic test (rK39-ICT; Kalazar Detect ${ }^{\text {tm }}$ Rapid test, InBIOS International, Seattle, WA), using $25 \mu \mathrm{l}$ of peripheral blood and following the manufacturer's instructions; and b) Immunofluorescence antibody test (IFAT) following a standard method, using $10 \mu \mathrm{l}$ of $2 \times 10^{7} \mathrm{~L}$. infantum promastigotes $/ \mathrm{ml}$ in $1 \times$ PBS per well as antigen (reference strain MHOM/FR/78/LEM-75) and $1 \mu \mathrm{l}$ plasma for the analysis. The IFAT threshold titre for positivity was $1 / 160$ [13]. Considering the present work a pilot study, replicate testing of the samples was not performed.

\section{Molecular diagnosis}

Parasite detection was done by means of nested-PCR targeting the Leishmania SSUrRNA gene (LnPCR) as described elsewhere, this protocol is Leishmania genus specific and uses the primer pair R221 (5'-GGT TCC TTT CCT GAT TTA CG-3') and R332 (5'-GGC CGG TAA AGG CCG AAT AG-3') in the first reaction, and the primer pair R223 (5'-TCC CAT CGC AAC CTC GGT T-3') and R333 (5'-AAA GCG GGC GCG GTG CTG-3') in the nested reaction [14]. Starting material for DNA extraction was: i) $100 \mu \mathrm{L} \mathrm{PB}$ and ii) the pellet obtained after centrifugation (6000 rpm in a benchtop microcentrifuge for $10 \mathrm{~min}$ ) and PBS $1 \times$ washing of the LN dilution obtained from each dog. DNA was extracted by conventional phenol-chloroform extraction and ethanol precipitation and further eluted in $100 \mu \mathrm{l}$ sterile distilled water.

\section{Molecular typing of the parasites}

Leishmania molecular typing was carried out by sequence analysis of both the LnPCR products obtained from PB and LN samples, and the ITS-1 PCR products obtained from PB samples of LnPCR positive dogs. ITS1 PCR was performed as described elsewhere with the primer pair LITSR (5'-CTG GAT CAT TTT CCG ATG-3') and L5.8S (5'-TGA TAC CAC TTA TCG CAC TT-3') and used only for typing purpose [15]. Direct sequencing of the PCR products was performed with forward and reverse primers; using the Big-Dye 
Terminator Cycle Sequencing Ready Reaction Kit V3.1 and the automated ABI PRISM 377 DNA sequencer (Applied Biosystems, Foster City, CA). Sequences obtained were analyzed and edited using Lasergene ${ }^{\circ}$ sequence analysis software (DNASTAR, Madison, WI).

\section{Statistical analyses}

Data recorded during the clinical examination and results from serological analyses were introduced in an Excel $^{\circ}$ data sheet (Microsoft Office 2003). The association between the different variables was analyzed with the SPSS statistical software version 16.0, using the chisquare test with Yate's correction. A p-value of $<0.05$ was considered as statistically significant.

\section{Results}

\section{Clinical examination}

Dogs were grouped according to their age in four different groups. Group 1 ( $\leq 1$ year) consisted in 23/110 dogs (20.9\%), group 2 (2-5 years) in 55/110 (50.0\%), group 3 (6-10 years) in $18 / 110(16.4 \%)$, and group 4 (>10 years) in $14 / 110(12.7 \%)$. Male/female ratio for all groups together was 1.5/1 (66 male/44 female). Eighty-three out of the 110 dogs (75.4\%) were mongrel and 27/110 (24.6\%) were from different breeds.

After clinical examination, 34 out of 110 dogs (30.9\%) were classified as asymptomatic, while 76/110 (69.1\%) presented one or more clinical signs related to canine leishmaniasis. The frequency of the different symptoms in the 76 symptomatic dogs is presented in table 1 . Nineteen out of the 76 symptomatic $(25 \%)$ dogs were classified as oligosymptomatic ( 1 or 2 symptoms), while $57(75 \%)$ were classified as polysymptomatic (more than 3 symptoms).

\section{Serological and molecular diagnosis}

All dogs were analyzed by rK39-ICT and/or IFAT. rK39-ICT was positive in $42 / 109$ (38.5\%) of the dogs, and IFAT in 40/102 (39.2\%). The combination of both serological methods indicated that $48 / 110(43.6 \%)$ of them were seropositive. For 101 dogs tested by both serological methods, the concordance between rK39-ICT and IFAT results was $90.1 \%$. Dogs were considered as

Table 1 Frequency of signs/symptoms related to canine leishmaniasis in $\mathbf{7 6}$ symptomatic dogs

\begin{tabular}{ll}
\hline Symptoms & Frequency (\%) \\
\hline Skin lesions & $73 / 76(96.0 \%)$ \\
Lymphadenopathy & $68 / 76(89.5 \%)$ \\
Onychogryphosis & $47 / 76(61.8 \%)$ \\
Weight loss & $38 / 76(50.0 \%)$ \\
Conjunctivitis & $32 / 76(42.1 \%)$ \\
\hline
\end{tabular}

seropositive when $\mathrm{rK} 39-\mathrm{ICT}$ and/or IFAT yielded a positive result.

All dogs were analysed by PB-LnPCR and/or LNLnPCR. Leishmania DNA was detected in PB of 23/109 (21.1\%) and in LN of $47 / 94$ (50.0\%) of the dogs studied. The combination of both PCR approaches detected the parasite DNA in 52/110 (47.3\%) dogs. For 93 dogs on which PCR was performed on both biological samples the concordance of PCR results was $63.4 \%$. Dogs were considered as parasite positive when leishmanial DNA was detected by PB-LnPCR and/or LN-LnPCR.

Dogs were considered as infected when they were seropositive and/or parasite positive. Table 2 provides a detailed description of serology and PCR results with regards to the origin, sex, breed, age group and clinical status of 110 dogs on which both serology and PCR data were available.

Figure 1 shows a flowchart including data on clinical examination, the number of samples processed by each diagnostic test and those testing positive. The number of dogs positive with one, two, three or four diagnostic approaches according to their clinical status is shown in Table 3.

Table 2 Detailed description of serology and PCR results with regards to different parameters in 110 dogs

\begin{tabular}{|c|c|c|c|c|}
\hline & & $\begin{array}{l}\text { Sero- } \\
\text { pos* }^{*}\end{array}$ & Parasite-pos ${ }^{* *}$ & Infected ${ }^{* * *}$ \\
\hline \multirow[t]{2}{*}{ Origin } & $\begin{array}{l}\text { Owner } \\
(\mathrm{N}=27)\end{array}$ & $14(51.8 \%)$ & $14(51.8 \%)$ & 18 (66.7\%) \\
\hline & $\begin{array}{l}\text { Canine shelter } \\
(\mathrm{N}=83)\end{array}$ & 34 (40.9\%) & 38 (45.8\%) & 45 (54.2\%) \\
\hline \multirow[t]{2}{*}{ Sex } & $\begin{array}{l}\text { Male } \\
(N=66)\end{array}$ & $30(45.4 \%)$ & $32(48.5 \%)$ & $40(60.6 \%)$ \\
\hline & $\begin{array}{l}\text { Female } \\
(\mathrm{N}=44)\end{array}$ & $18(40.9 \%)$ & $20(45.4 \%)$ & $23(52.3 \%)$ \\
\hline \multirow[t]{2}{*}{ Breed } & $\begin{array}{l}\text { Defined breed } \\
(\mathrm{N}=27)\end{array}$ & $16(59.2 \%)$ & $11(40.7 \%)$ & 16 (59.2\%) \\
\hline & $\begin{array}{l}\text { Mongrel } \\
(\mathrm{N}=83)\end{array}$ & $32(38.5 \%)$ & $41(49.4 \%)$ & 47 (56.6\%) \\
\hline \multirow[t]{4}{*}{$\begin{array}{l}\text { Age } \\
\text { Group }\end{array}$} & $\begin{array}{l}\text { Group } 1 \\
(\mathrm{~N}=23)\end{array}$ & $12(52.2 \%)$ & $12(52.2 \%)$ & 15 (65.2\%) \\
\hline & $\begin{array}{l}\text { Group } 2 \\
(\mathrm{~N}=55)\end{array}$ & $24(43.6 \%)$ & $29(52.7 \%)$ & 34 (61.8\%) \\
\hline & $\begin{array}{l}\text { Group } 3 \\
(N=18)\end{array}$ & $5(27.8 \%)$ & 7 (38.9\%) & 7 (38.9\%) \\
\hline & $\begin{array}{l}\text { Group } 4 \\
(N=14)\end{array}$ & 7 (50.0\%) & $4(28.6 \%)$ & 7 (50.0\%) \\
\hline \multirow[t]{2}{*}{$\begin{array}{l}\text { Clinical } \\
\text { status }\end{array}$} & $\begin{array}{l}\text { Symptomatic } \\
(N=76)\end{array}$ & $39(51.3 \%)$ & $42(55.3 \%)$ & $50(65.8 \%)$ \\
\hline & $\begin{array}{l}\text { Asymptomatic } \\
(\mathrm{N}=34)\end{array}$ & $9(26.5 \%)$ & $10(29.4 \%)$ & 13 (38.2\%) \\
\hline Total & $(N=110)$ & 48 (43.6\%) & 52 (47.3\%) & 63 (57.3\%) \\
\hline
\end{tabular}

*Sero-pos: seropositive by rK39-ICT and/or IFAT. **Parasite-pos: LnPCR positive on PB and/or LN samples. ***Infected: Sero-pos and/or Parasite-pos. 


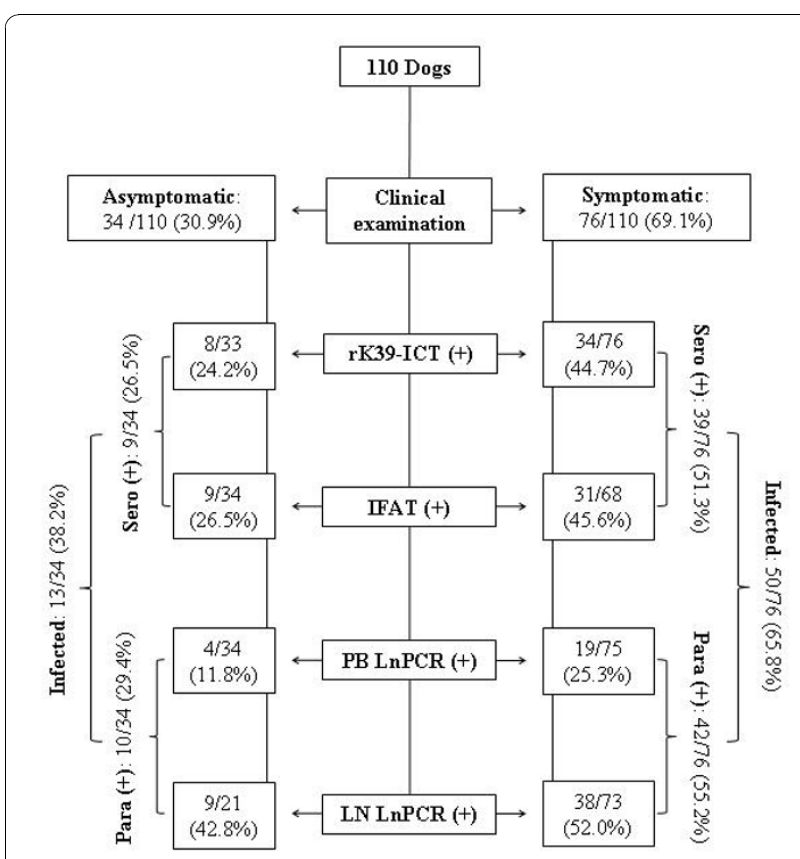

Figure 1 Flowchart including data on clinical examination, the number of samples processed by each diagnostic test and those testing positive. Flowchart including data on clinical examination, and number of samples processed. Sero (+): seropositive by rK39-ICT and/or IFAT. Para (+):LnPCR positive on PB and/or LN samples. Infected: Sero (+) and/or Para (+).

\section{Molecular typing of the parasites}

DNA sequences from LnPCR products were obtained for $23 \mathrm{~PB}$ and $45 \mathrm{LN}$ samples from 53 different dogs. And DNA sequences from ITS-1 PCR products were obtained for PB samples from 17 different dogs. Once edited the sequences obtained were used for BLAST search against GenBank $^{\mathrm{m}}$ database [16]. The sequences obtained from the LnPCR products returned 100\% identity with SSUrRNA gene sequences of Leishmania donovani complex species (L. infantum, L. donovani), while the sequences obtained from the ITS-1 PCR products returned 100\% identity with ITS-1 sequences of L. infantum.

\section{Statistical analyses}

No statistical association was observed between infection and age group $(\mathrm{p}=0.279)$, sex $(\mathrm{p}=0.387)$ or origin $(\mathrm{p}=0.256)$. However there was a significant association between symptomatology and infection $(p=0.007)$. Furthermore, a significant association between number of symptoms and infection $(\mathrm{p}=0.019)$ was observed. Particularly, the presence of the following symptoms presented significant association with infection: lymphadenopathy, onychogryphosys and conjunctivitis $(\mathrm{p}<0.05)$; while skin lesions and weight loss were not associated ( $\mathrm{p}>0.05)$.

\section{Discussion}

Leishmania infection was confirmed either by molecular and/or serological methods in 63/110 (57.3\%) dogs. Current entomological data reporting the presence of $L u$. longipalpis in Posadas [9], together with the presence of $L$. infantum infection in urban dogs indicates that the transmission cycle of zoonotic VL (ZVL) could be well established, and that further cases of human VL are likely to appear. It has been shown in Brazil that human epidemics of VL are usually preceded, or concomitant to high infection rates in the canine population [17-19]. The emergence of 58 human VL cases in Posadas since 2006 supports this possibility. The limitations of this pilot study, based on a convenience sampling, do not allow drawing solid conclusions. In addition most of the dogs $(83 / 110)$ were from a canine shelter, thus the data do not have the power of a population-based random sampling study to provide a view of the real prevalence of Leishmania infection in the canine population. However the data present a consistent picture of this emerging focus of ZVL.

Infected symptomatic dogs are considered to be the main reservoirs of ZVL leishmaniasis, in the present study these represent $45.4 \%(50 / 110)$ of the dogs studied. However, infected asymptomatic dogs are also said to play a role in transmission [20-22], in this study these represent $11.8 \%(13 / 110)$ of the total. In spite of the statistical association between infection and symptomatology, the present study also highlights the low specificity of the clinical diagnosis of CanL; in fact $34.2 \%(26 / 76)$ of the symptomatic dogs (one or more of the before mentioned symptoms) presented negative results for both serology and PCR. Thus, as suggested by recent reviews, reliable laboratory-based diagnostic tests should

Table 3 Number of dogs analyzed by all 4 diagnostic methods testing positive with one, two, three or four diagnostic approaches (rK39-ICT, IFAT, PB-LnPCR and LN-LnPCR) according to their clinical status

\begin{tabular}{cccc}
\hline Number of positive tests & Total $\mathbf{N}=\mathbf{8 5}(\mathbf{\%})$ & Asymptomatic $\mathbf{N}=\mathbf{2 0}(\%)$ & Symptomatic $\mathbf{N}=\mathbf{6 5}(\%)$ \\
\hline $\mathbf{0}$ & $32 / 85(37.6)$ & $11 / 20(55.0)$ & $21 / 65(32.3)$ \\
\hline $\mathbf{1}$ & $14 / 85(16.4)$ & $3 / 20(15.0)$ & $11 / 65(16.9)$ \\
\hline $\mathbf{2}$ & $10 / 85(11.7)$ & $1 / 20(5.0)$ & $9 / 65(13.8)$ \\
\hline $\mathbf{3}$ & $15 / 85(17.6)$ & $2 / 20(10.0)$ & $13 / 65(20.0)$ \\
\hline $\mathbf{4}$ & $14 / 85(16.4)$ & $3 / 20(15.0)$ & $11 / 65(16.9)$ \\
\hline
\end{tabular}


be carried out either in clinical practice or in epidemiological studies [23,24].

In areas where $\mathrm{ZVL}$ is endemic the prevalence of infected dogs tends to be high, with a greater proportion of asymptomatic ones [25]. In the present study, and unlike what happens in traditional endemic areas for ZVL, most of the infected dogs were symptomatic. This could be due to a recent introduction of $L$. infantum in the area where, as a naive population, most of the dogs infected would develop the disease. It is also reported in ZVL endemic areas an increasing prevalence of seropositive dogs with age, and a final decrease in those aged $\geq 7$ years [26-28]. In dogs from the present study we observed no increase in seropositivity nor in parasite DNA detection related with the age of the dogs ( $p>$ $0.05)$. This finding could also be consistent with the hypothesis of a recent introduction of L. infantum. The results of the diagnostic tests employed also support the above mentioned. In the recent review by Baneth, et al. [29] it is stated that in endemic foci the number of PCR positive dogs will exceed the number of seropositive; however in the present study there were no great differences between the rates of infection detected by serology and PCR.

Concerning the serological test employed in this study (rK39-ICT and IFAT) they have presented a concordance of $90.1 \%$. IFAT has long been considered as the gold standard in canine leishmaniasis serodiagnosis $[1,30]$, and different rK39 rapid tests have also shown a good performance in field studies [31]. According to different authors their sensitivity ranges from 85.5 to $90 \%$ for IFAT and 72 to $96.7 \%$ for rK39-ICT, while their specificity ranges from 94.7 to $100 \%$ for IFAT and $61.75-100 \%$ for rK39-ICT [24,31-33]. However, Mettler et al [33] reported a lower sensitivity for these methods in asymptomatic infected dogs, $29.4 \%$ for IFAT and $52.9 \%$ for rK39-ICT. In our study no big differences were observed in the performance of these tests between asymptomatic and symptomatic dogs; In PCR-positive asymptomatic dogs rK39-ICT and IFAT were positive for $55.5 \%$ and $60 \%$ of the dogs respectively, while in PCR-positive symptomatic dogs both methods were positive for $66.6 \%$ of the dogs. Cross reactions with other infectious agents such as Babesia canis, Ehrlichia canis, Neospora caninum, Hepatozoon canis and Trypanosoma cruzi have also been described $[31,33,34]$. Some false-positive results of rK39-ICT have been also attributed to unknown blood factors present in dog blood [32]. Although we cannot categorically rule out cross-reactions with $T$. cruzi or L. braziliensis in our study, this is very unlikely as the presence of autochthonous infections by these parasites has not been reported in the city of Posadas, where this study took place.
With regards to the molecular typing of the parasites this is, to our knowledge and taking into account the review by Salomón et al. [9], the first report on molecular identification of autochthonous L. infantum infection in Argentina.

The recently established focus of human and canine VL in Asunción, Paraguay $[35,36]$, could have been, because of its proximity, the source of the introduction of VL in Northern Argentina [37]. To ascertain the origin of the parasites in this new VL focus a wide population genetics based study involving L. infantum strains from different South American endemic areas could be very helpful. For this purpose multi locus microsatellite typing seems to be the most appropriate tool [38]. And to ascertain since when it is established, powerful epidemiological studies in human and canine population must be done. These studies should address: i) retrospective analyses of human and canine samples from patients/dogs attending the different health/veterinary centres in the area with symptoms compatible with human VL/CanL; ii) leishmanin skin test (in humans) and serological surveys (in both humans and dogs) to estimate the prevalence of parasite contact in different age groups.

\section{Conclusions}

This pilot study confirms the presence of CanL due to L. infantum in Posadas (Misiones, Argentina), an area where the disease has been recently reported. Though the present work has the limitations of not being a population-based random sampling study, and does not provide an accurate view of the real prevalence of Leishmania infection in the canine population of Posadas, it indicates that this new VL focus could be well established, and further work is needed to ascertain its magnitude and to prevent further human VL cases.

\section{Acknowledgements}

This work was supported by: Dirección General de Cooperación al Desarrollo, Generalitat Valenciana, Spain. And European Commission 6th Framework Programme INCO-CT-2005-015407 (Control strategies for visceral leishmaniasis $(\mathrm{VL})$ and mucocutaneous leishmaniasis $(\mathrm{MCL})$ in South America: Applications of molecular epidemiology/LeishEpiNetSA).

We especially acknowledge the essential collaboration of the canine shelters' responsible from the non-profit civil association 'El Refugio' and the

Municipal Animal Health Institute-IMUSA. We would also like to thank Lucy A. Parker (Área de Salud Pública, Universidad Miguel Hernández de Elche, Alicante, Spain) for reviewing and editing of the manuscript.

\section{Author details}

'WHO Collaborating Centre for Leishmaniasis, Servicio de Parasitología, Centro Nacional de Microbiología, Instituto de Salud Carlos III, Ctra. Majadahonda-Pozuelo, km 2, 28220 Majadahonda-Madrid, Spain. ${ }^{2}$ Área de Parasitología, Universidad Miguel Hernández, Ctra. de Valencia km 8.7, 03550 Elche-Alicante, Spain. ${ }^{3}$ Cátedra de Parasitología, Facultad de Ciencias Exactas, Químicas y Naturales, Universidad Nacional de Misiones, 3300 Posadas, Misiones, Argentina. ${ }^{4}$ Ministerio de Salud Pública de Misiones, 3300 Posadas, Misiones, Argentina. 


\section{Authors' contributions}

IC, LA, FJBL and JD conceptualized and designed the study. IC and LA drafted the manuscript; CC critically reviewed it and contributed to its design. FJBL coordinated the study. LA, MNG and JD contacted the dog owners and canine shelter that participated in the study. LA and MNG carried out clinical examination and obtained biological samples from the dogs. JN and MNG designed the protocol for clinical scoring of the dogs. IC, $L A$, JN and CC performed serological and molecular diagnosis. IC performed molecular typing of the parasites. All authors participated in the analysis and interpretation of data, revised the different draft versions, and read and approved the final manuscript.

\section{Competing interests}

The authors declare that they have no competing interests.

Received: 24 June 2010 Accepted: 1 December 2010 Published: 1 December 2010

\section{References}

1. Alvar J, Cañavate C, Molina R, Moreno J, Nieto J: Canine Leishmaniasis. Adv Parasitol 2004, 57:1-88

2. Dantas-Torres F: Canine leishmaniosis in South America. Parasit Vectors 2009, 2(Suppl 1):S1.

3. Desjeux P: Leishmaniasis: current situation and new perspectives. Comp Immunol Microbiol Infect Dis 2004, 27:305-318.

4. Dujardin JC: Risk factors in the spread of leishmaniases: towards integrated monitoring? Trends Parasitol 2006, 22:4-6.

5. Shaw J: The leishmaniases - survival and expansion in a changing world. A mini-review. Mem Inst Oswaldo Cruz 2007, 102:541-547.

6. World Health Organization, Geneva: Urbanization: an increasing risk factor for leishmaniasis. Wkly Epidemiol Rec 2002, 44:365-370.

7. Costa CHN: Characterization and speculations on the urbanization of visceral leishmaniasis in Brazil. Cad Saúde Pública 2008, 24:2959-2963.

8. Silva MR, Marques MJ, Romanha AJ, de Almeida Santa-Rosa IC, Carneiro CM, Barbosa Reis A: Autochthonous canine visceral leishmaniasis in a nonendemic area: Bom Sucesso, Minas Gerais State, Brazil. Cad Saude Publica 2008, 24:281-286.

9. Salomón OD, Sinagra A, Nevot MC, Barberian G, Paulin P, Estevez J, Riarte A, Estevez J: First visceral leishmaniasis focus in Argentina. Mem Inst Oswaldo Cruz 2008, 103:109-111.

10. Salomón OD, Sosa Estani S, Rossi GC, Spinelli GR: Presencia de Lutzomyia longipalpis y situación de la leishmaniosis visceral en Argentina. Medicina (B Aires) 2001, 61:174-178.

11. Deschutter J, Piragine R, Silva G, Bernard H, Borchichi S, Von Steiger L, Jordá G, Acosta L, Cruz I, Bornay-Llinares FJ: Leishmaniosis visceral humana (LVH) en Misiones (Argentina). Estudio descriptivo retrospectivo (2006-2009). XIX Congreso Latinoamericano de Parasitología: 22-24 October 2009; Asunción, Paraguay Federación Latinoamericana de Parasitología-FLAP; 2009, 233

12. Gobierno de la provincia de Misiones. [http://www.misiones.gov.ar/index php?option=com_frontpage\&ltemid=1].

13. Bray RS: Immunodiagnosis of leishmaniasis. In Leishmaniasis. Edited by: Chang KP, Bray RS. Amsterdam, The Netherlands, Elsevier; 1985:177-182.

14. Cruz I, Chicharro C, Nieto J, Bailo B, Cañavate C, Figueras MC, Alvar J: Comparison of new diagnostic tools for management of pediatric Mediterranean visceral leishmaniasis. J Clin Microbiol 2006, 44:2343-2347.

15. Schönian G, Nasereddin A, Dinse N, Schweynoch C, Schallig HDFH, Presber W, Jaffe CL: PCR diagnosis and characterization of Leishmania in local and imported clinical samples. Diagn Microbiol Infect Dis 2003, 47:349-358.

16. Basic Local Alignment Search Tool. [http://blast.ncbi.nlm.nih.gov/Blast.cgi].

17. Margonari C, Freitas CR, Ribeiro RC, Moura ACM, Timbó M, Gripp AH, Pessanha JP, Dias ES: Epidemiology of visceral leishmaniasis through spatial analysis, in Belo Horizonte municipality, state of Minas Gerais, Brazil. Mem Inst Oswaldo Cruz 2006, 101:31-38.

18. Werneck GL, Costa CHN, Walker AM, David JR, Wand M, Maguire JH: Multilevel modeling of the incidence of visceral leishmaniasis in Teresina, Brazil. Epidemiol Infect 2007, 135:195-201.
19. Queiroz PVS, Monteiro GRG, Macedo VPS, Rocha MAC, Batista LMM, Queiroz JW, Jerônimo SMB, Ximenes MFFM: Canine visceral leishmaniasis in urban and rural areas of Northeast Brazil. Res Vet Sci 2009, 86:267-273.

20. Molina R, Amela C, Nieto J, San-Andrés M, González F, Castillo JA, Lucientes J, Alvar J: Infectivity of dogs naturally infected with Leishmania infantum to colonized Phlebotomus perniciosus. Trans $R$ Soc Trop Med Hyg 1994, 88:491-493.

21. Michalsky EM, Rocha MF, da Rocha Lima AC, França-Silva JC, Pires MQ, Oliveira FS, Pacheco RS, dos Santos SL, Barata RA, Romanha AJ, FortesDias CL, Dias ES: Infectivity of seropositive dogs, showing different clinical forms of leishmaniasis, to Lutzomyia longipalpis phlebotomine sand flies. Vet Parasitol 2007, 147:67-76.

22. Da Costa-Val AP, Cavalcanti RR, de Figueiredo Gontijo N, Michalick MS, Alexander B, Williams P, Melo MN: Canine visceral leishmaniasis: relationships between clinical status, humoral immune response, haematology and Lutzomyia (Lutzomyia) longipalpis infectivity. Vet J 2007, 174:636-643.

23. Miró G, Cardoso L, Pennisi MG, Oliva G, Baneth G: Canine leishmaniosisnew concepts and insights on an expanding zoonosis: part two. Trends Parasitol 2008, 24:371-377.

24. Maia C, Campino L: Methods for diagnosis of canine leishmaniasis and immune response to infection. Vet Parasitol 2008, 158:274-287.

25. Dantas-Torres F, Brito MEF, Brandâo-Filho SP: Seroepidemiological survey on canine leishmaniasis among dogs from an urban area of Brazil. Vet Parasitol 2006, 140:54-60

26. Martínez Cruz MS, Martínez Moreno A, Martínez Moreno FJ, Martínez Gómez F, Hernández Rodríguez S: Epidemiología de la leishmaniosis canina en Córdoba. Revista Ibérica de Parasitología 1990, 50:1-7.

27. Abranches P, Silva-Pereira MCD, Conceiçao-Silva FM, Santos Gomes GM, Janz JG: Canine leishmaniasis: pathological and ecological factors influencing transmission of infection. J Parasitol 1991, 77:557-561.

28. Fisa R, Gállego M, Castillejo S, Aisa MJ, Serra T, Riera C, Carrió J, Gállego J, Portús M: Epidemiology of canine leishmaniosis in Catalonia (Spain) The example of the Priorat focus. Vet Parasitol 1999, 83:87-97.

29. Baneth G, Koutinas AF, Solano-Gállego L, Bourdeau P, Ferrer L: Canine leishmaniosis - new concepts and insights on an expanding zoonosis: part one. Trends Parasitol 2008, 24:324-330.

30. Gradoni L: The diagnosis of canine leishmaniasis. Canine Leishmaniasis: moving towards a solution. Proceedings of the second international canine leishmaniasis forum, Sevilla, Spain Intervet International; 2002, 7-14.

31. Lemos EM, Laurenti MD, Batistela Moreira MA, Barbosa Reis A, Cordeiro Giunchetti R, Raychaudhuri S, Dietze R: Canine visceral leishmaniasis: performance of a rapid diagnostic test (Kalazar Detect ${ }^{\mathrm{TM}}$ ) on dogs with and without signs of the disease. Acta Trop 2008, 107:205-207.

32. Reithinger R, Quinnell RJ, Alexander B, Davies CR: Rapid detection of Leishmania infantum infection in dogs: Comparative study using an immunochromatographic dipstick test, enzyme-linked immunosorbent assay, and PCR. J Clin Microbiol 2002, 40:2352-2356.

33. Mettler M, Grimm F, Capelli G, Camp H, Deplazes P: Evaluation of enzymelinked immunosorbent assays, an immunofluorescent-antibody test, and two rapid tests (immunochromatographic-dipstick and gel tests) for serological diagnosis of symptomatic and asymptomatic Leishmania infections in dogs. J Clin Microbiol 2005, 43:5515-5519.

34. Mancianti F, Pedonese F, Poli A: Evaluation of dot enzyme-linked immunosorbent assay (dot-ELISA) for the serodiagnosis of canine leishmaniasis as compared with indirect immunofluorescence assay. Vet Parasitol 1996, 65:1-9.

35. Canese A: Leishmaniosis visceral canina en el área metropolitana de la "Gran Asunción", Paraguay. Medicina (B Aires) 2000, 60(Supl III):65.

36. Cousiño B: Vigilancia y Control de la Leishmaniasis en el Paraguay. Informe Final de la Reunión de Expertos OPS/OMS sobre Leishmaniasis Visceral en las Américas, Panaftosa, Rio de Janeiro, Brazil Organización Panamericana de la Salud; 2006, 34-36.

37. Salomón OD, Quintana MG, Bruno MR, Quiriconi RV, Cabral V: Visceral leishmaniasis in border areas: clustered distribution of phlebotomine sand flies in Clorinda, Argentina. Mem Inst Oswaldo Cruz 2009, 104:801-804. 
38. Kuhls K, Keilonat L, Ochsenreither S, Schaar M, Schweynoch C, Presber W, Schönian G: Multilocus microsatellite typing (MLMT) reveals genetically isolated populations between and within the main endemic regions of visceral leishmaniasis. Microbes Infect 2007, 9:334-343.

Pre-publication history

The pre-publication history for this paper can be accessed here: http://www.biomedcentral.com/1471-2334/10/342/prepub

doi:10.1186/1471-2334-10-342

Cite this article as: Cruz et al:: A canine leishmaniasis pilot survey in an emerging focus of visceral leishmaniasis: Posadas (Misiones, Argentina). BMC Infectious Diseases 2010 10:342.

Submit your next manuscript to BioMed Central and take full advantage of:

- Convenient online submission

- Thorough peer review

- No space constraints or color figure charges

- Immediate publication on acceptance

- Inclusion in PubMed, CAS, Scopus and Google Scholar

- Research which is freely available for redistribution

Submit your manuscript at www.biomedcentral.com/submit
C Biomed Central 